\title{
Risk-Perception Formation Considering Tangible and Non-Tangible Aspects of Cycling: A Flemish Case Study
}

\author{
Zain Ul-Abdin *(D), Pieter De Winne and Hans De Backer \\ Department of Civil Engineering, Ghent University, Technologiepark, 609052 Zwijnaarde, Belgium; \\ p.dewinne@ugent.be (P.D.W.); hans.debacker@ugent.be (H.D.B.) \\ * Correspondence: zain.ulabdin@ugent.be; Tel.: +32-9-264-5431
}

Received: 26 October 2019; Accepted: 14 November 2019; Published: 18 November 2019

\begin{abstract}
Risk perception influences cycling attributes toward its adoption. Researchers are investigating attributes associated with risk formation. In this study, various attributes were selected which influence the user's formation of risk perception. For this purpose, an online questionnaire survey was conducted in Flanders, among all segments of the population $(\mathrm{N}=774)$. Participants were asked questions for attributes relating to risk formation. Results suggested that risk formation among users evolves around tangible to non-tangible attributes. The spectrum of risk perception was developed which visualizes risk evolution, considering various attributes. Surprisingly, elements such as "comfort", surface evenness, and policies were rated as being neutral. Infrastructure and the presence of opposite road users tend to be foreseen as critical factors for risk formation. Risk perception varies depending upon psychometric paradigm shifts, such as dread and unknown risk. This strange notion is considered to lie in a space between dread and unknown risk. This explains the difference in risk perception, knowingly or not knowingly (subconsciously), yet expressing cognitively and evolving inside. This is an interesting finding, but reasons behind such a motive need to be explained. A possible explanation behind such behavior is that people tend to change their responses due to knowledge acquisition during the survey.
\end{abstract}

Keywords: risk perception; bicycle safety; traffic safety; behavioral aspects; infrastructure; vulnerable road users

\section{Introduction}

Cycling is considered a global mobility solution to issues such as congestion, health, environment, and socioeconomic impact. However, factors affecting cycling-adoption levels need to be investigated in detail. Perception formation for a specific facility, vale, bicycling, is dependent upon multiple factors, i.e., previous experience, infrastructure, local measures, and environmental aspects.

Road-traffic risk perception is dependent on fear and sensation [1]. Separate cycling paths are considered more secure than mixed motorized bicycle lanes [2]. Interaction of cyclists with other modes raises the risk levels [3], while Jacobsen [4] reveals that a higher number of presence of road users increases safety perception. Experience increases the adaption level for risks. Variant risk perception is subjective and also ranges from person-to-person personal characteristics and attributes [5]. Choosing a particular strategy for avoiding traffic interactions may eventually lead to a reduction of objective risk levels. Perceived behavioral control refers to individual perception to execute a particular action [6]. Perceived behavioral control refers to self-perception regarding the ability and resulting quality toward doing an action. For cyclists, this is linked to how skilled and efficient they are at avoiding troublesome situations. Reduced risk levels are observed when perceived behavioral control is high [7]. Higher 
perceived control stimulates a cyclist to engage and ride in an unsafe situation, i.e., mixed-traffic situation [8]. But higher perceived control may lead to overconfidence, leading to a dangerous situation [9].

To foresee behavioral aspects for cycling, and considering variant attitudinal factors considering risk perception, Flanders was selected. Flanders is interesting since it possesses a relatively higher number of cyclists, with alarming higher perceived risk, flat terrain, and good cycling culture. Bicycle use is remarkable in Flanders, engaging in utilitarian needs. Employers and the government have already introduced policies that stimulate bicycle use. Yet lower cycling levels raise concern over the safety aspect of the current system. Perception of risk is considered influential in choice adoption in various situations, especially for cyclist's safety outcomes [9]. Higher perceived risk leads us to foresee how, where, which factors need to be investigated, or shall be invested later on to increase cycling adoption.

With previous stated studies, it reflects an immense urge to investigate the factors behind setting risk perception for cyclists. Moreover, these factors shall be investigated, validated, and contra relationship shall be investigated with different behavioral aspects, stimuli (policies that influence cycling adoption), and barriers. This has not yet been addressed, which will help to foresee interesting inferences together. The urge to investigate psychological factors concerning risk perception needs to be used to provide better policy management and safer traffic attitudes. Table 1 shows an overview of different investigated factors for this study.

Table 1. Overview of the investigated factors associated with risk formation for cycling.

\begin{tabular}{ll}
\hline \multicolumn{1}{c}{ Influencing Factors for Cycling } & \multicolumn{1}{c}{ Features Explained According to Category } \\
\hline Suggestions for improvement & $\begin{array}{l}\text { Separate paths dashed lanes [10], change to bicycle street, ban entry } \\
\text { for a car. } \\
\text { Accessibility [11], cost, congestion, or stimulus [10]. }\end{array}$ \\
$\begin{array}{l}\text { Factors implicating motivation } \\
\text { Cognitive factors for choice adoption }\end{array}$ & $\begin{array}{l}\text { Infrastructure, safety, policy [12] or weather. } \\
\text { Public transport [13], bicycle-sharing program [14], taxi or peer } \\
\text { help [15] }\end{array}$ \\
Alternate to bicycle usage & $\begin{array}{l}\text { Safe, disaster, needs improvement, convenient but } \\
\text { needs improvement. }\end{array}$ \\
Perceived safety levels new TDMs & $\begin{array}{l}\text { Dangerous intersections [16,17], uneven surfaces [18], waiting } \\
\text { time, hilliness. }\end{array}$ \\
Hindrance toward usage & $\begin{array}{l}\text { Sharp curves, uneven surface, Presence of cars, lesser road width or } \\
\text { hilliness [19]. }\end{array}$ \\
Critical features for infrastructure & Distance, infrastructure [20], security or repair facilities. \\
Prioritized factors for usage & Safety in numbers, green environment, traffic calming measures, \\
Comparative critical cognitive factors & or prioritized bicycle path. \\
Impact of TDMs & Dashed colored separate trails, Bicycle street, or ban car entry [21]. \\
\hline
\end{tabular}

This manuscript is further divided into different sections for better readability and structure. Section 2 provides the literature review in the scope of this study. Section 3 describes materials and methods opted for this study. Section 4 elaborates on the results, including its discussion. Section 5 concludes this study.

\section{Literature Review}

Conventional traffic-safety approaches focus on road environment and vehicles. The bicycle as a mode choice has a significant influence by public policies, TDMs, and infrastructure. This has been extensively investigated by Pucher and Dill [10] by looking into 14 different case studies. Pucher and Dill [10] conclude that those programs eventually encourage bicycle usage. However, abrupt increases may result in better bicycle usage. This can be achieved by integrating multiple policies, systems, infrastructure, and land usage. Rode and Floater [11] conclude that accessibility in cities is dependent upon multiple factors, i.e., spatial planning, traffic trajectories, urban development, urban sprawl, 
public transport planning, and policies. Long-term campaigning among young adolescents results in better mode adoption, i.e., environmentally friendly modes [12,13]. A smart bicycle system was evaluated in London to foresee a combined effect of a bicycle with public transport. It was found that the potential of a smart bicycle system lies between leisure, recreational activities, market, and use of public transport [14]. Active mobility, i.e., bicycling and walking, has prominent effects among pupils in the universityTo be noted, higher bicycle trips result in lesser motorized usage and chance of accident occurrence. Intersections are a critical part of infrastructure $[15,16]$. They are a common meeting point of all types of road users, i.e., motorized or non-motorized road users. Results from Madsen and Lahrmann [17] suggest better visibility, higher segregation, and better design into lesser cyclists and motorized interaction. Worldwide cities have been introducing mobility plans to improve the mobility situation. A credible effort has been made by municipality of Pierus in its new mobility plan to transport, environment, and traffic flow issues. Infrastructure for has the most prominent effect, especially for bicycle usage. This is evident in prominent Dutch and Danish cities. Better the infrastructure results in higher cycled trips [20,21]. According to Bakogiannis and Vassi [22], developed cities, such as Peirus, have integrated cycling in their mobility policies, thus leading to becoming a sustainable mobility prototype for the Greek environment. However, this manuscript does not evaluate new mobility regulations in Flanders, even though they were recently introduced because of its scope. This shall be addressed in future studies. Sanders [23] investigated the relationship of risk formation with frequency and experience. Concluding that perceived risk is negatively influenced by the decision to bicycle. The decision to bicycle increases with frequency, whereas the experience of cyclists reveal that near misses have significant influence than actual accidents for perceived risk [23]. Large cities face the dominance of car which demotivates bicycle usage due to issues, i.e., space, urban transformation, attitudes, social acceptance and car dominance [24]. Perceived risk is a critical factor for bicycle adoption or ridership both in developed and underdeveloped countries. Perceived risk lessens as experience increase. Cyclists are motivated to cycle due to health, environment, accessibility, time and monetary reasons. Whereas they are discouraged by factors such as perceived crash risk, safety and weather conditions [25]. According to Willis, Manaugh [26] literature review of 24 previous studies reveal that social factors are considered more important than infrastructure and safety for bicycle adoption.

User perception of the environment, stimulus, individual experience, and personal characteristics influence user choice for a specific mode play a significant role in modal choice [27]. According to Gössling and Humpe [27], risk-perception association is effected by considerable cycled distance. Larger-distance cycling is associated with avoiding risks, traffic impact, air, and noise pollution. This ultimately results in higher socioeconomic monetary costs. Risk formation plays a critical role in how users interact with the environment [28]. Explaining user preferences for associated traffic behavior for a particular mode, i.e., bicycling. According to Strauss, Miranda-Moreno [29] found a non-linear association between traffic volume and injury occurrence on intersections. Kummeneje, Ryeng [30] found that risk perception is associated with cognitive parameters, i.e., "worry", which influences a cyclist's cycling frequency and decision to opt for cycling or not. Prati and Puchades [31] concluded that a cycler's perceived risk and control (confidence) are positively associated with bicycle adoption. However, negatively associated with motorized traffic interaction. The risks associated with electric bicycle accidents were investigated by Yao and $\mathrm{Wu}$ [32] in China. Results conclude that driving license results in lower crashes. Male riders, and aggressive and erroneous riding result into more accidents. Personality traits also have a significant impact on cycling risk perception, i.e., aggression, altruism, anxiety, and altruism, whereas risky driving behavior is associated with personality formation, regulated by attitudinal determinants [33]. Although these personality traits are essential, they do not fall into the scope of this study. A risk-perception comparison was made between respondents of Turkey and Norway. According to Şimşekoğlu and Nordfjærn [34], their study results reveal that road safety behavior and attitudes played a significant role in risk formation among Norwegian respondents but not among Turkish respondents, thus, concluding that risk perception varies among respondents 
for traffic safety, culture, and development levels, respectively [34]. Risk-perception formation varies among countries due to their respective traffic-safety conditions, user attitudes, driving behavior, cultural differences, and socioeconomic conditions $[35,36]$.

This research attempts to address the research gaps mentioned in the above studies. The above-stated parameters influence risk formation significantly. This includes investigating parameters in which users interact regularly.

Risk-perception formation is considered a broad term in the accident-analysis context. Although it is influenced by multiple aspects, its formation is not well-defined, especially for regions like Flanders. Therefore, this study aims to analyze, form, and visualize risk-perception formation according to tangible or not tangible aspects, i.e., infrastructure, peer pressure, etc.

\section{Materials and Methods}

An online questionnaire survey was conducted between 1 November and 24 December 2018, through online means in Flanders.

With new mobility regulations having been introduced in Flanders, VRUs or weak road users in Dutch such as non-motorized traffic users, i.e., bicycle and pedestrians, were encouraged to participate in traffic. Nevertheless, the higher risk associated with current conditions hinders them from doing so. The survey was evaluated critically through pilot means. Academicians, Professionals, cyclist clubs, and mentors who are engaged in cycling activities actively provided detailed insight. Later, the survey was improved by following their recommendations.

For reducing self-selection bias, a wider audience was attracted from a variety of socio-demographic groups from different locations. The survey was disseminated through cyclist associations, social media groups, bicycle-sharing points, and community forums, in order to attract a larger audience. For reaching a wider audience, a small link with flash messages was distributed. Later, the advertised link possessed a detailed description of the study, along with its aims.

As seen in Figure 1a, a total of 824 participants responded, and 774 participants were recruited for analysis. Figure $1 \mathrm{~b}$ reveals that mixed responses with an inclination toward "risky" were recorded about the risk perception of current conditions. The excluded participants came from the age group that did not fall under the scope of this study (under 18 and over 65) and were also underrepresented. Underrepresented data categories yield into unrealistic inferences. Therefore, participants in the age groups under 18 and $65+$ were removed.

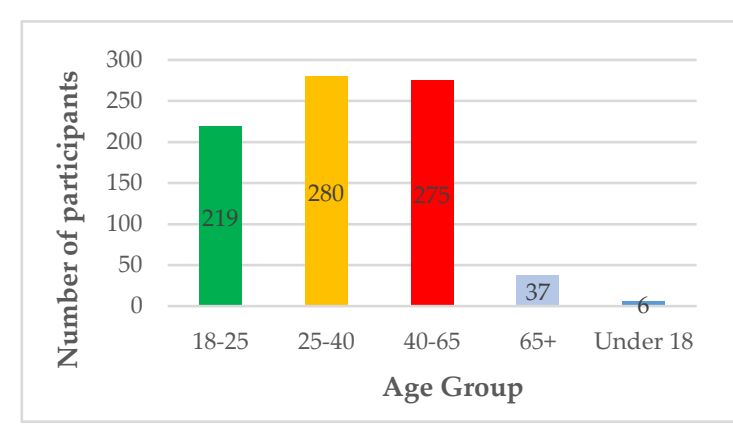

(a)

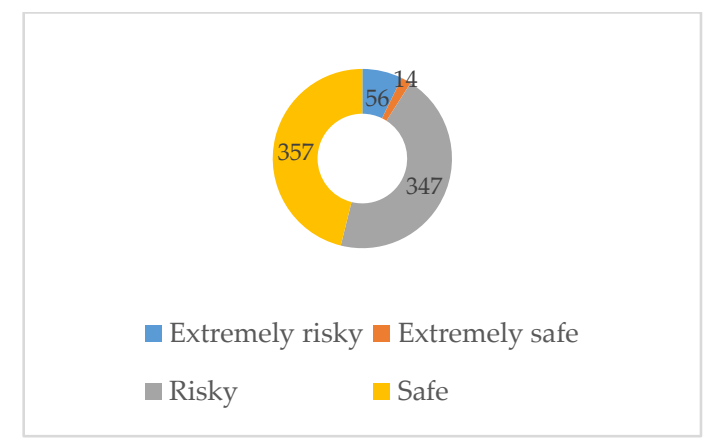

(b)

Figure 1. (a) Age distribution among participants; (b) risk perception of current conditions.

\section{Results}

The dataset was subjected to the test of normality to check the randomness. Later, the dataset is discussed with the association between variables, utilizing the Chi-square test of independence and Kruskal-Wallis $\mathrm{H}$ test for differences. The Chi-square test of independence determines whether there is an association between two nominal variables. Cramer's $V$ value represents the strength of the relationship in numeric form. The Kruskal-Wallis $\mathrm{H}$ test is a nonparametric test which determines 
significant differences among a foreseen group of variables. The Kruskal-Wallis $\mathrm{H}$ test determines the stochastic dominance of one sample or not, but it does not determine the occurrence of stochastic dominance. Degree of freedom is an estimate of parameters equal to the number of independent scores that go into estimate minus number of parameters used as intermediate steps for its estimation.

Table A2 in Appendix A shows frequency and distribution for the dataset. Results are stated in Table 2 (Chi-square test of association) and Table 3 (Kruskal-Wallis $\mathrm{H}$ test); the results are discussed below w.r.t. current risk perception in Flanders.

Table 2. Chi-square test distribution considering risk levels.

\begin{tabular}{ccccc}
\hline Investigated Variables with $\boldsymbol{\chi}^{\mathbf{2}}$ Test & $\begin{array}{c}\text { Pearson } \\
\text { Chi-Square Value }\end{array}$ & df & $\boldsymbol{p}$-Value & $\begin{array}{c}\text { Cramer's } \\
\boldsymbol{V} \text { Value }\end{array}$ \\
\hline Age & 10.506 & 6 & 0.105 & 0.802 \\
Distance & 24.747 & 15 & 0.053 & 0.103 \\
Motivation bicycle use & 26.895 & 24 & 0.309 & 0.108 \\
Attitudes toward problems related cycling & 15.305 & 9 & 0.083 & 0.081 \\
Attitude toward new mobility regulations & 119.174 & 12 & 0.002 & 0.227 \\
Suggestions for improving safety at intersections & 5.085 & 9 & 0.827 & 0.047 \\
Important factor for modal shift to bicycle usage & 17.235 & 9 & 0.045 & 0.086 \\
Perception during busy period & 35.914 & 9 & 0.000 & 0.124 \\
Infrastructural factors effecting bicycling & 30.881 & 12 & 0.002 & 0.115 \\
Obstacles in cycling & 26.818 & 12 & 0.008 & 0.107 \\
Perceived behavioral factors for cycling & 26.957 & 9 & 0.001 & 0.108 \\
Delineated colored bicycle paths & 21.811 & 9 & 0.009 & 0.168 \\
Perceived behavioral infrastructure & 9.115 & 9 & 0.427 & 0.063 \\
\hline
\end{tabular}

Table 3. Kruskal-Wallis H test for differences between means, according to risk levels.

\begin{tabular}{cccc}
\hline Investigated Variables & Kruskal-Wallis H & df & $p$-Value \\
\hline Age & 9.483 & 3 & 0.024 \\
Distance & 11.492 & 3 & 0.009 \\
Motivation bicycle use & 1.037 & 3 & 0.792 \\
Attitudes toward problems related cycling & 5.333 & 3 & 0.149 \\
Attitude toward new mobility regulations & 72.730 & 3 & 0.000 \\
Suggestions for improving safety at intersections & 0.603 & 3 & 0.896 \\
Important factor for modal shift to bicycle usage & 6.839 & 3 & 0.077 \\
Perception during busy period & 13.675 & 3 & 0.003 \\
Infrastructural factors effecting bicycling & 1.467 & 3 & 0.69 \\
Obstacles in cycling & 8.285 & 3 & 0.04 \\
Perceived behavioral factors for cycling & 18.802 & 3 & 0 \\
Delineated colored bicycle paths & 6.303 & 3 & 0.098 \\
Perceived behavioral infrastructure & 6.225 & 3 & 0.101 \\
\hline
\end{tabular}

\section{Discussion}

As seen in Figure 2a and Table 3, risk perception changes according to age qua experience with $p<0.05$. The higher number of bicycled $\mathrm{km}$ leads to higher exposure to various conditions, i.e., infrastructure, environment, and cyclist behavior. It is interesting to see experienced cyclists (higher bicycled $\mathrm{km}$ ) tend to rate conditions "Risky", whereas less-experienced cyclists (lower bicycled km) rate conditions as safe, hence confirming the conclusion of Heinen and Maat [37] that longer-distance bicycle commutes play a significant role, since attentiveness increases, and the user enjoys a better attitude and has better. Figure $2 \mathrm{~b}$ confirms that longer distances ultimately result in better user experience, more exposure to conditions, and a better understanding of risk. Where this study notably differs from the conclusion by Heinen and Maat [37] is that a higher cycling distance is not a significant predictor for the safety perception. 


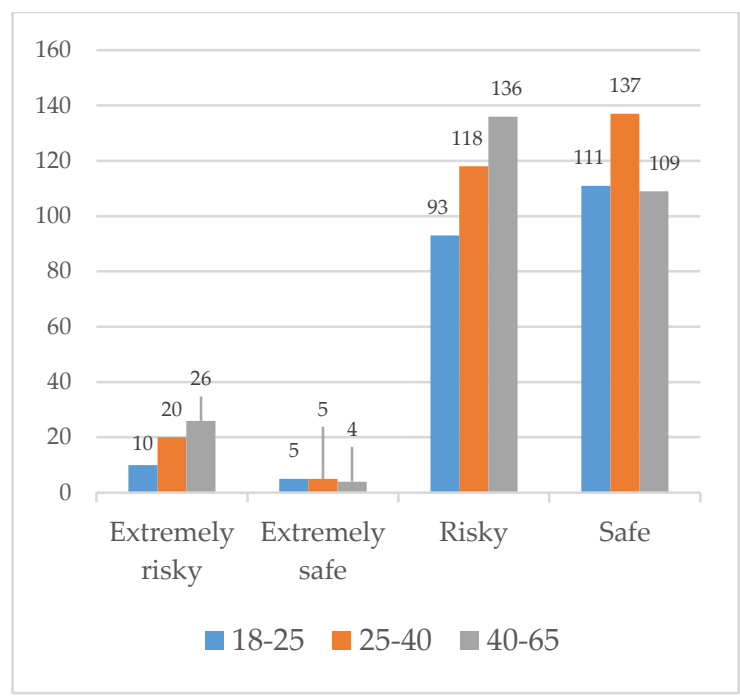

(a)

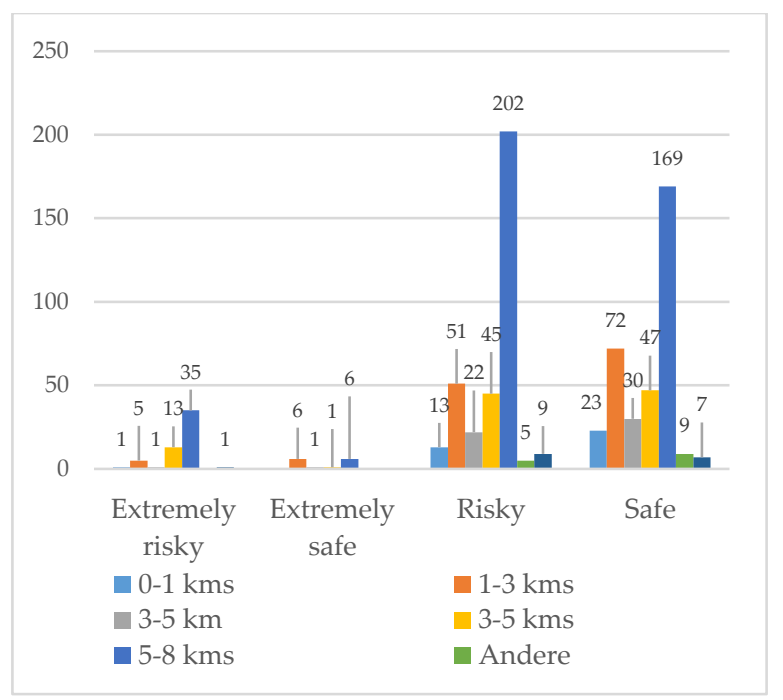

(b)

Figure 2. (a) Risk perception of current conditions, according to age category; (b) risk perception in terms of distance.

Older users tend to rate current conditions as "Risky" ( $\mathrm{N}=136)$, as noted in Figure 2a. In Figure 3a, parameters such as an improvement in infrastructure and attractiveness are considered important for increasing risk levels from "Risky" to "Safe". The previously stated parameters are more related to traffic safety. Another important observation noted in Figure 3a is that respondents who consider perception levels as "Safe" tend to pursue cycling as a recreational activity, i.e., interaction with nature, which shall be treated as a source of attractiveness. Meanwhile, in Figure $2 b$ it is previously noted that cyclists who use cycling for shorted distance rate current system as "Safe", too. With current risk perception w.r.t varying distance in $\mathrm{km}^{\prime} \mathrm{s}$ with $\chi^{2}(15)=24.747, p=0.05$, Cramer's $V$ value $=0.103$, and Kruskal-Wallis $H$ test value (3) $=11.492$ and $p$-value $=0.009$. In Figure 3a, it is a cognitively undisguised that users who mainly bicycle for pleasure or recreational activities consider cycling to be safe due to the reason that they are exposed less to the general cycling experience. Thus, a green environment means that the "recreational green feeling" is induced, which influences cycling decisions about risk perception. Cognitively indulging cyclists to shift their cognitive priorities from safety to leisure or attractiveness is thus an important policy to consider. This is a very interesting observation since it only complies with two parameters, "Safety and Attractiveness", of the guidelines issued by the European Commission for cycling infrastructures [38,39]. Meanwhile, for risk formation, the parameters "Coherence, Comfort, and Directness" are considered to be not important here.

Figure 3a shows that respondents who rate the current perception as "Risky" tend to prefer the presence of "Separate, prioritized bicycle paths $(\mathrm{N}=173)$ " or "Traffic measures $(\mathrm{N}=54)$ ", while respondents who opted to consider the current perception as "Safe" had more an inclination toward "Presence of green environment $(\mathrm{N}=132)$ ". It is interesting to note that respondents who rate the current systems as "Safe" opt for using bicycles as a tool for direct interaction with nature. However, in the end, the distributions were evenly distributed with no significant $p$-value to cycling for risk perception. This may be noted in $\chi^{2}(9)=15.305, p=0.083$, Cramer's $V$ value $=0.081$, and Kruskal-Wallis $H$ test value $(3)=5.333$ and $p$-value $=0.149$.

Figure $3 \mathrm{~b}$ shows that road users who rely more on a sustainable option of alternate travel tend to rate it as "Safe", i.e., bus/tram ( $\mathrm{N}=194)$, while the reliance on peer support (i.e., car use) is seen as a "Riskier" option $(\mathrm{N}=152)$. This behavior may be because users are already adopted to sustainable modes of travel and prefer other sustainable travel modes as a reliable option. 


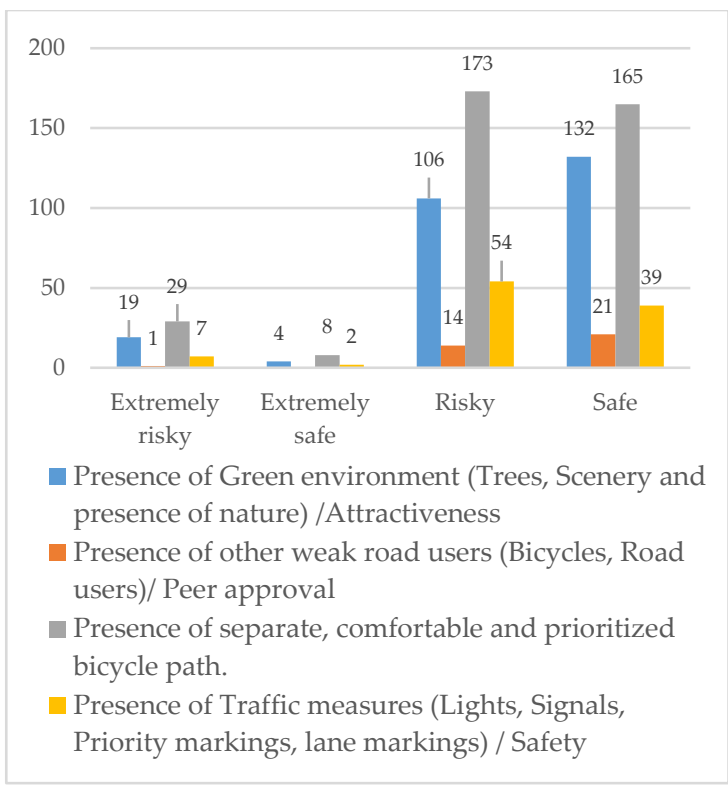

(a)

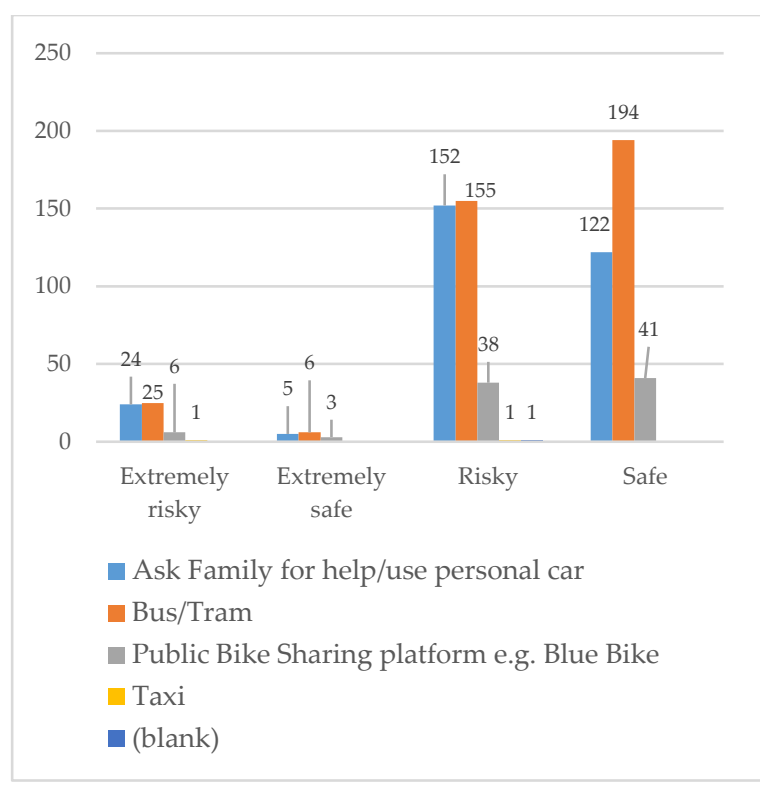

(b)

Figure 3. (a) Motivation to cycle in terms of risk perception; (b) attitudes toward problems.

Figure 4a shows satisfaction toward mobility regulations, considering different risk levels. It is interesting to see that cyclists who rate current systems as "Risky" tend to choose "Overall convenience with care on dangerous intersections $(\mathrm{N}=276,79.53 \%)$ ", but people who rate the current systems as "Safe" ( $\mathrm{N}=251,70.30 \%)$ also tend to choose "Overall convenience with care on dangerous intersections" with small decline "Safe and cycle every day $(\mathrm{N}=89,24.92 \%)$ " and a small increase, with results as $\chi^{2}(12)=119.174, p=0.002$, Cramer's $V$ value $=0.227$, Kruskal-Wallis $H$ test value (3) $=72.73$, and $p$-value $<0.05$. This eventually means that respondents feel that current systems are "Risky $(\mathrm{N}=347)$ ", and yet are cognitively evaluating mobility regulations, still foreseeing dangerous intersections. A possible explanation is that, since those regulations only consist of traffic-sign measures with no infrastructural changes, i.e., bicycle streets (where cyclists have priority over motorized road users), one-way streets and banning car entry. In Flanders, banning car entry to specific streets or areas was introduced to give more freedom and access to non-motorized road users, with an exception for motorized road users who are residents. If those regulations had had any infrastructural improvement, i.e., segregation, elevation, and reconstruction, then they may have resulted as more effective into cognitive recognition.

It is interesting to note that, in Figure $4 \mathrm{~b}$, a gradual shift in risk levels was noted from "Safe" to "Risky", reducing the responses $(\mathrm{N}=24)$ for "Separation colored/dashed bicycle lanes". This indicates that the segregation of bicycle paths is associated with safety, which confirms the finding of Thomas and DeRobertis [40]. The majority choose "Separate elevated bicycle path $(\mathrm{N}=121,72.35 \%)$ as "Risky" as the highest indicator, with nonsignificant association $\chi^{2}(9)=5.085, p$-value $=0.827$, and no variation in medians for different risk levels with Kruskal-Wallis $H$ test value (3) $=0.603$ and $p$-value $=0.896$. Figure 3a reveals that the motivation to cycle does not change with different risk levels. Respondents who rate the current perception as "Risky" tend to prefer the presence of "Separate, prioritized bicycle paths $(\mathrm{N}=173)$ " or "Traffic measures $(\mathrm{N}=54)$ ". Figure $4 \mathrm{~b}$ reveals suggestions from road users to increase safety, while considering different parameters. It shows how suggestions very cognitively considering risk perception. Here, "Risk" is associated with the presence of motorized users and its possible interaction resulting in large exposure. At the same time, "Safety" is associated with infrastructural improvement, independence, and authority. 


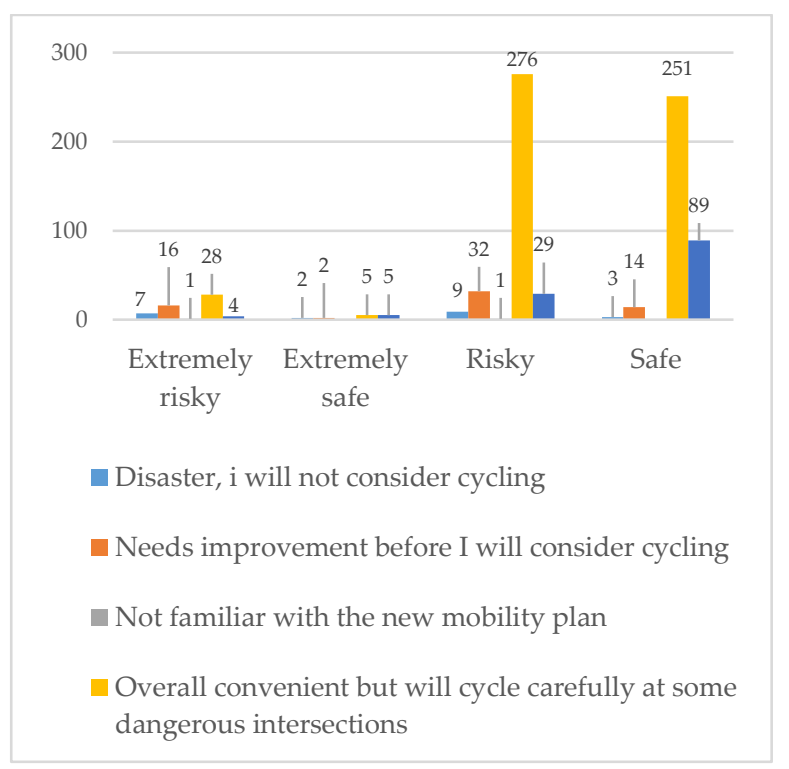

(a)

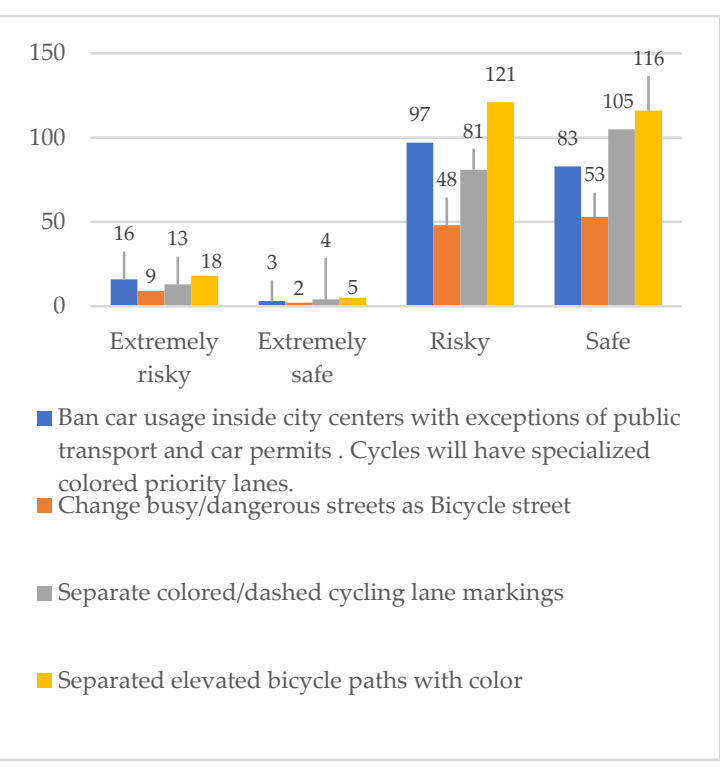

(b)

Figure 4. (a) Current mobility regulations satisfaction level in terms of risk perception; (b) suggestions for improving safety, considering risk perception.

Figure 5 a shows that the majority choose "Infrastructure $(\mathrm{N}=169,48.70 \%)$ " as "Risky" as the highest indicator with nonsignificant association $\chi^{2}(9)=17.235, p=0.045$, Cramer's $V$ value $=0.086$, and no variation in medians for different risk levels with Kruskal-Wallis test value (3) $=6.836$ and $p$-value $=0.077$. For this study, infrastructural features deemed "Risky" are considered to be the most critical factors for a modal shift. The above conclusions from Figures $4 \mathrm{~b}$ and $5 \mathrm{a}$ confirm the conclusion of Akar and Clifton [41] that separate bicycle trails encourage people to cycle, while intervention programs and policy stimulate cycling [10].

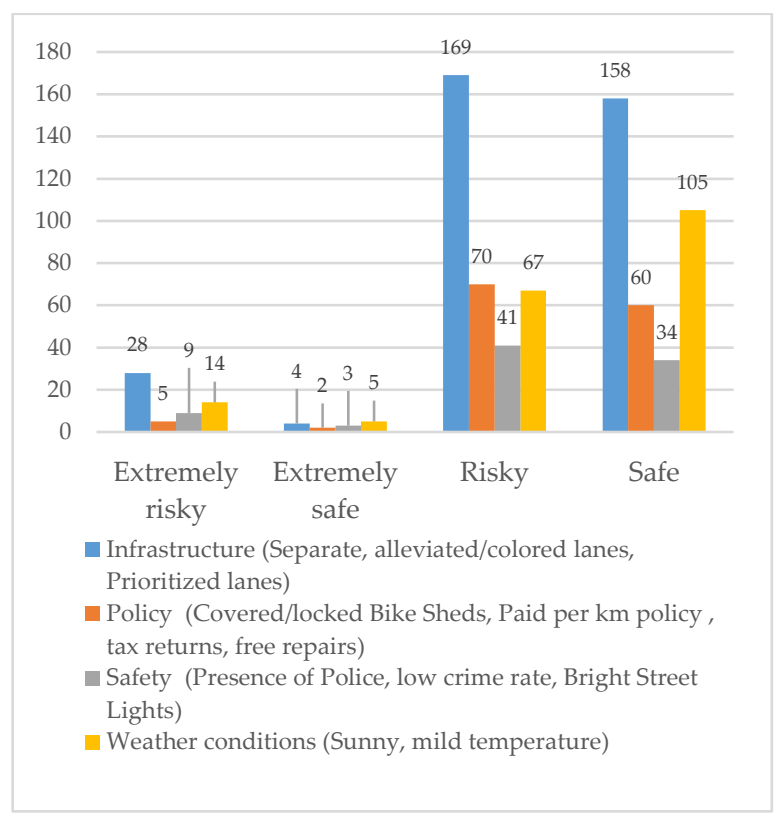

(a)

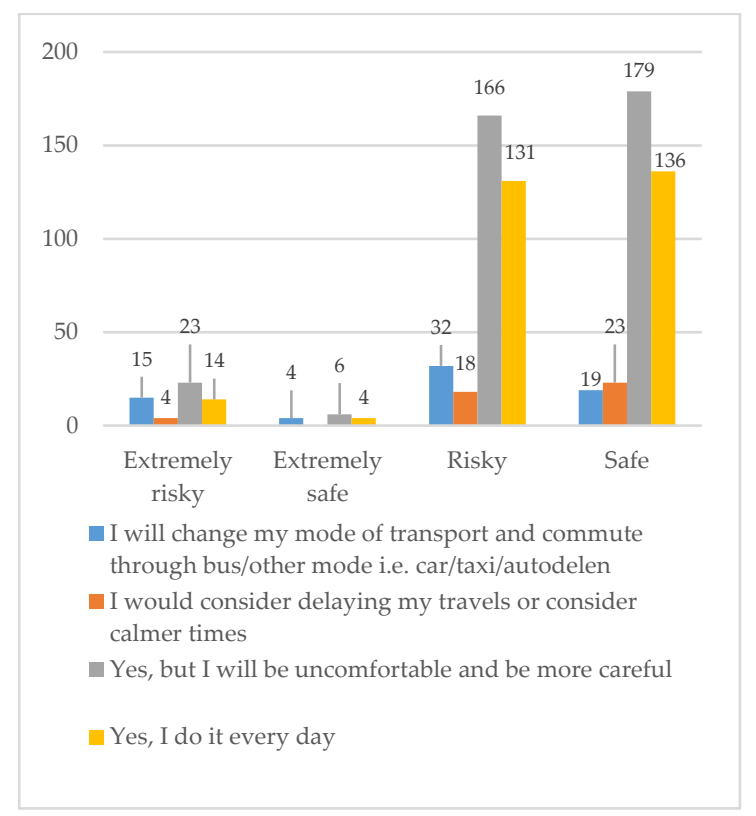

(b)

Figure 5. (a) Critical factors for modal shift considering risk perception. (b) Perception of safety during busy periods. 
Figure $5 \mathrm{~b}$ points at the fact that users do not want to shift their mode in case of an increased presence of other road users. This may be noted in $\chi^{2}(9)=35.914, p<0.05$, Cramer's $V$ value $=0.124$, and Kruskal-Wallis test value (3) $=13.675$ and $p$-value $=0.003$. It is interesting to see that this conclusion is not in accordance with Dill and McNeil [42], who state that segregation of trails is positively associated with comfort levels and cycling rates since the investigated people were pro-cyclists (the enthused and confident). This may be explained since active people in Flanders cognitively consider cycling as a better option for accessibility, comparing it relatively with other active mobility options. This may be due to time savings, availability, and economical options being compared with public transport. While new mobility regulations might also play a significant role in the formation of this behavior, since recent measures give more priority and freedom to cyclists, this conforms with "Directness", as indicated in EU regulations $[39,43]$.

Figure 6a shows what the critical factors are, when looking at infrastructure, which influence risk perception. Interaction between different road users, i.e., active and passive play a critical role in the formation of the "Risky" risk perception. This might be noted as $\chi^{2}(12)=30.88, p=0.002$, Cramer's $V$ value $=0.115$, and Kruskal-Wallis test value $(3)=1.467$ and $p$-value $=0.69$. This conclusion aligns with the "safety in numbers" effect by Fishman and Schepers [44], which states that the presence of cyclists increases safety and awareness, whereas other infrastructural features that directly influence cyclists' risk perception, i.e., "sharp curves" and "road width", are surprisingly considered less important. This conclusion is not in accordance with the belief that geometric features such as curvature and width are important to prevent accidents/injuries [45]. Geometry cannot be overlooked when designing intersections [19], intersection size, and bicycle lanes are positively associated with safety [46]. Features such as curvature, radius, width, and surface are considered to be critical for designing a cycling network and for comfort levels [18,47].

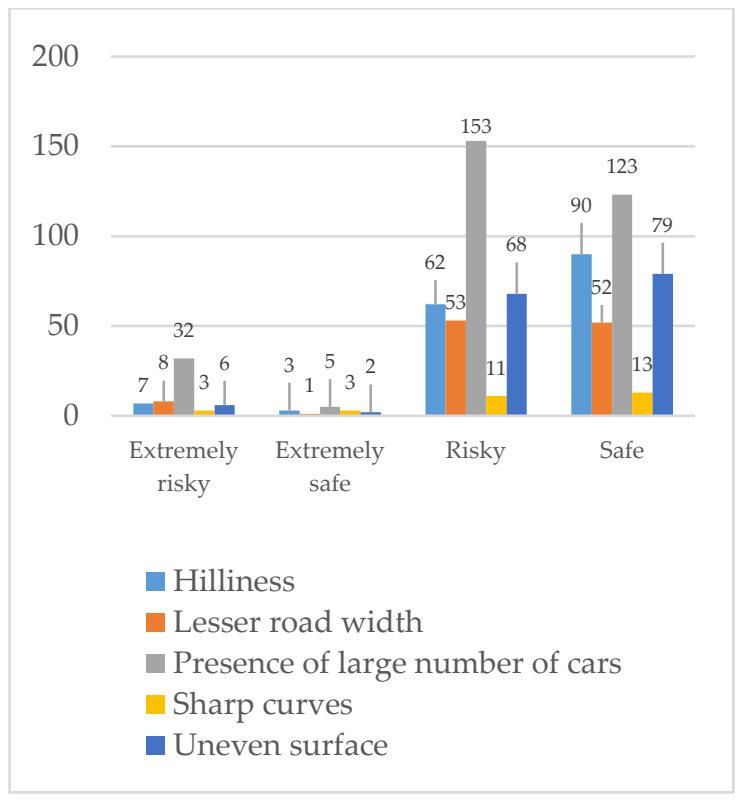

(a)

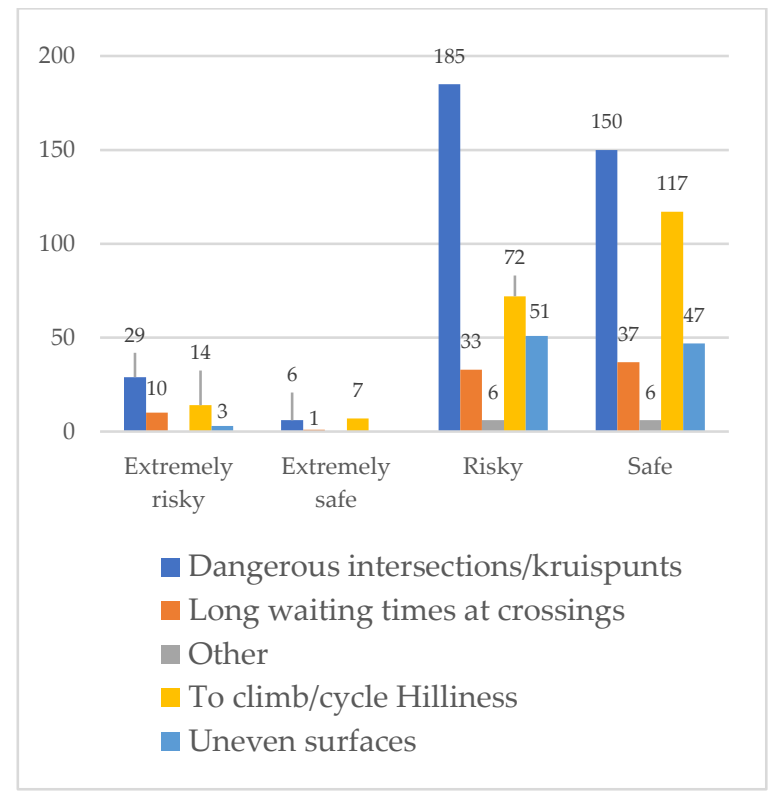

(b)

Figure 6. (a) Factors influencing not to cycle in terms of infrastructure, considering risk perception; (b) obstacles leading not to cycle in terms of risk perception.

Figure $6 \mathrm{~b}$ reveals the obstacles leading people not to cycle, considering different risk levels. Respondents who rated current infrastructure as "Risky" opted for "Dangerous intersections ( $\mathrm{N}=185$, $53.31 \%$ )" and "Hilliness $(\mathrm{N}=72,20.74 \%)$ ". This means infrastructure, i.e., safety over intersections, is considered to be important. This may be noted in $\chi^{2}(12)=26.818, p=0.008$, Cramer's $V$ value $=0.107$, and Kruskal-Wallis test value (3) $=8.285$ and $p$-value $=0.04$. While a gradual shift was noted among respondents who rated risk perception as "Safe". A gradual increase was noted in the category 
"Hilliness ( $\mathrm{N}=117,32.73 \%)$ ". It is interesting to see that users find "Hilliness" cognitively as "Safe". This conclusion is in accordance with Strauss and Miranda-Moreno [29], who found that proximity toward intersections and the involvement of multiple types of vehicles causes accidents. To be noted is that only dangerous intersections have a mixed traffic involvement, which leads to increased exposure among active (motorized) or passive road users (VRUs), hence leading to an increased chance of involvement in maneuvering.

Figure $7 \mathrm{a}$ reflects Figure $4 \mathrm{~b}$ in a more visually representative form. Figure $7 \mathrm{~b}$ shows that "Shorter distances" are also associated with "Safe" risk levels, and a gradual shift was also observed from "Risky $(\mathrm{N}=72,20.74 \%)$ " to "Safe $(\mathrm{N}=111,31.09 \%)$ ". Moreover, a majority of participants $(\mathrm{N}=246)$ rated "Coherent, effective infrastructure" systems as "Risky", considering situations where cyclists find it the most important. The respondents tended to opt for "Coherent, effective infrastructure" among all conditions risky or safe. Thus, this is primarily a significant predictor that cyclists find important. In Figure $7 \mathrm{~b}$, the majority choose "Coherent, effective infrastructure ( $\mathrm{N}=482$ for total), $(\mathrm{N}=246$ for Risky)" with a significant association and variation in medians for different risk levels. This means infrastructure, i.e., safety over intersections, is considered to be important. This may be noted in $\chi^{2}(9)=26.957, p=0.001$, Cramer's $V$ value $=0.108$, and Kruskal-Wallis $H$ test value $(3)=18.803$ and $p$-value $<0.05$.

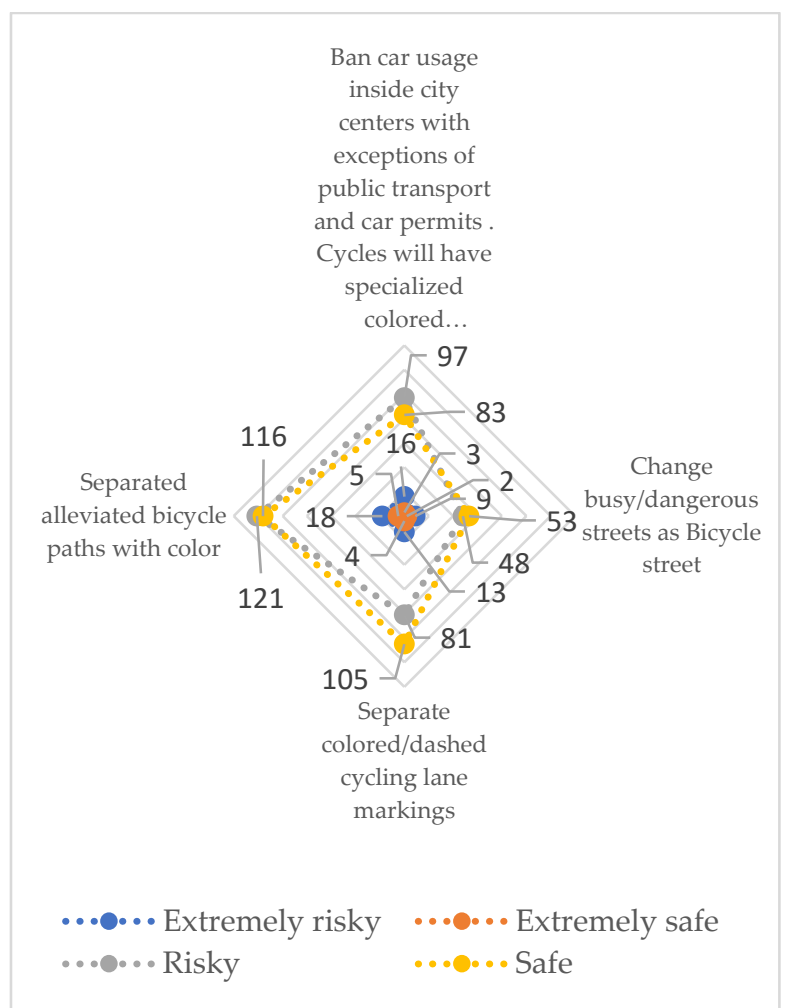

(a)

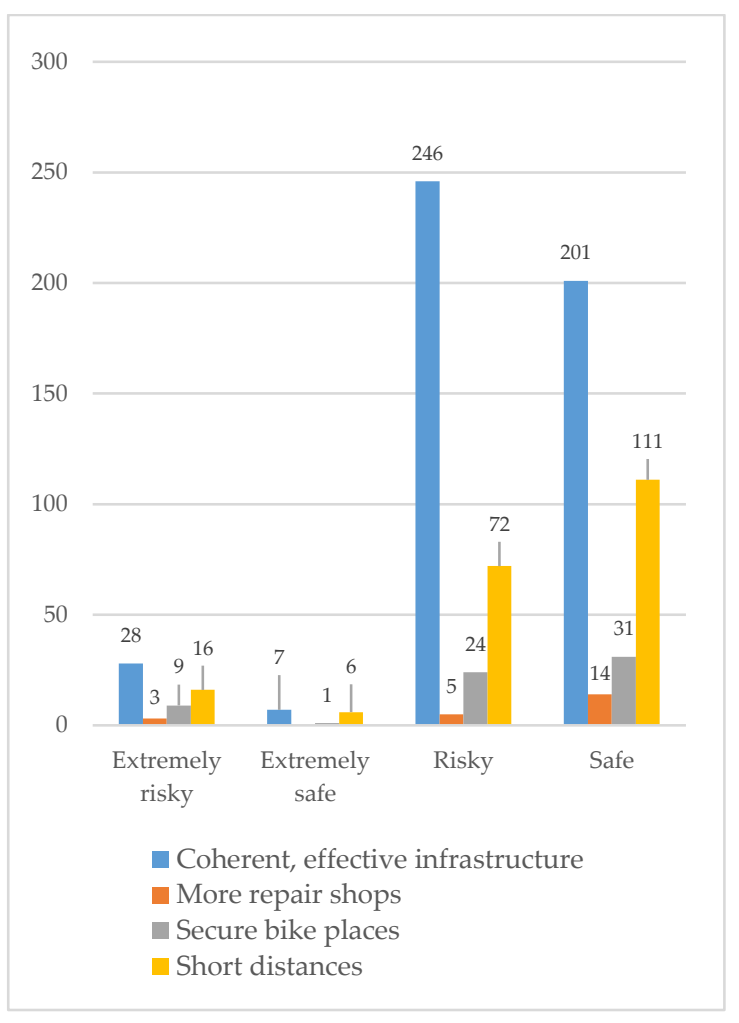

(b)

Figure 7. (a) Suggestions for improving safety perception; (b) perceived behavioral control (situations the rider finds most important) for cycling.

This conclusion aligns with the conclusion of safe cycling shall be addressed by reducing the risk inside intersections [20], and good infrastructure supports cycling especially among adults [48].

Here, for this research, respondents consider infrastructural aspects as a critical feature w.r.t. qua "Perceived behavioral factors", "Obstacles", "Modal shift", and "Suggestions for improvement". This clarifies and validates the effect among the importance of "Infrastructure" among active mobility users in Flanders, Belgium. Moreover, a majority of numbers $(\mathrm{N}=246)$ were rated as "Coherent, 
effective infrastructure", rating the current system as "Risky", considering situations where cyclists find it the most important.

In Figure 8a, the majority of those who rated current conditions as "Safe" had a response with "No effect" $(\mathrm{N}=169)$, which explains quite well that users who are already in the habit of cycling frequently consider current systems as safe enough to cycle. The majority choose "No effect $(\mathrm{N}=336$ considering both risky and safe stimuli), $(\mathrm{N}=169$ for Safe)" with the significant association and no variation in medians for different risk levels. This may be noted in $\chi^{2}(9)=21.811, p=0.009$, Cramer's $V$ value $=0.168$, Kruskal-Wallis $H$ test value $(3)=6.303$, and $p$-value $=0.098$. Not considering an elevated bicycle path as important (No effect $=169)$ means that cyclists are more comfortable sharing their space with other road users. This is strange since, previously, it was noted that cyclists are more comfortable in their independent personal space than in sharing their space, which makes them more exposed to other road users.

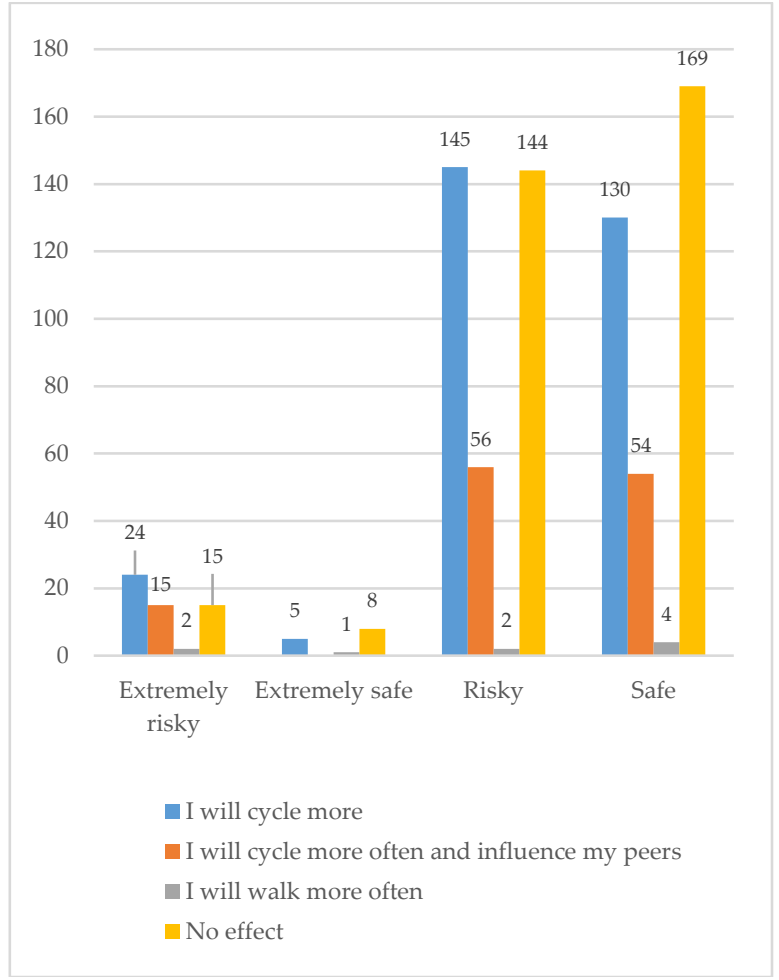

(a)

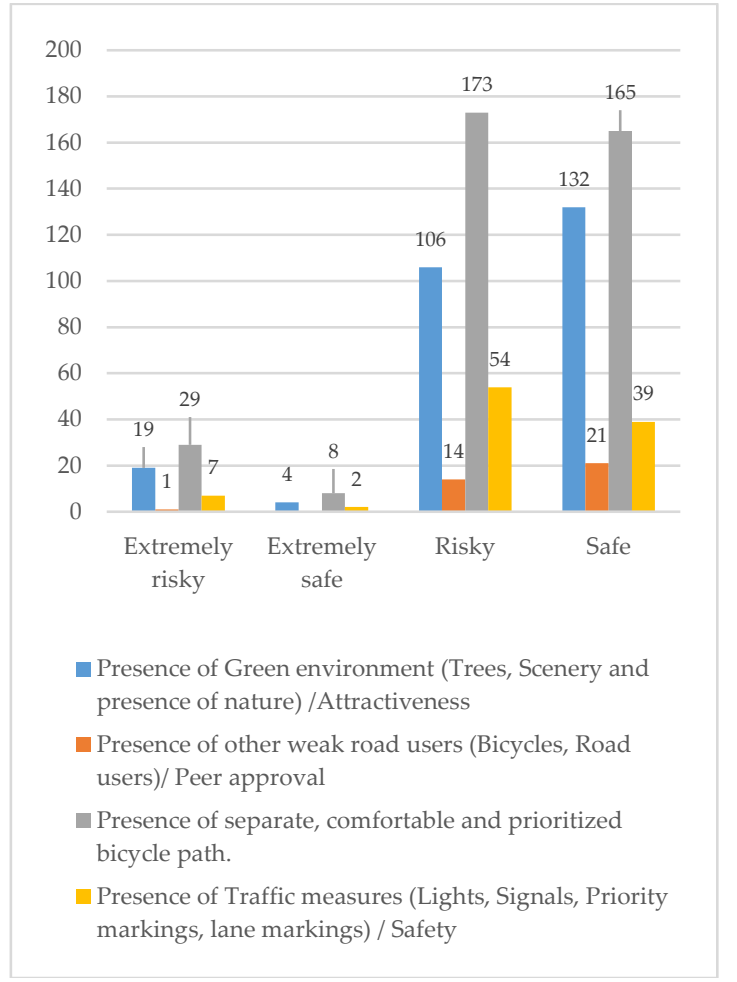

(b)

Figure 8. (a) Prioritized and elevated bicycle paths in terms of risk perception. (b) Perceived behavioral (critical things which motivate to cycle) w.r.t risk perception.

Moreover, this also reverses the effect of safety in numbers. Respondents who consider current systems as "Risky" are also tilted toward more "No effect $(\mathrm{N}=144)$ ". In Figure $8 \mathrm{~b}$ a mix response was received for features that motivate to cycle. A very mixed distribution was noted among users who rate systems as "Risky" and "Safe", whereas the majority tilted toward "Presence of comfortable, separate bicycle path".

The majority choose "Presence of separate, comfortable and prioritized bicycle path $(\mathrm{N}=375$ for total), $(\mathrm{N}=173$ for Risky level)", with no significant association and no variation in medians for different risk levels. This may be noted in $\chi^{2}(9)=9.115, p=0.427$, Cramer's $V$ value $=0.063$, and Kruskal-Wallis $H$ test value $(3)=6.225$ and $p$-value $=0.101$.

After infrastructure aspects, the element that motivates users most to take a day out cycling is interaction with nature, which refreshes them and is considered a sign of attractiveness according to the manual [39]. It must be noted that "Attractiveness" is considered to have sub-determinants: infrastructure and traffic measures. Nevertheless, this study shows that cognitive sub-determinants 
are identified as a separate entity. Here "Attractiveness" is seen by riders as an interaction with nature, giving a sense of freedom, individuality, and leisure. History reveals humanity's continuous interaction with nature. With the new age of urbanism, cities such as Tokyo, Beijing, and Mumbai have seen continuous infrastructural development where interaction with nature was reduced, which is quite evident in large cities i.e., Kuala lumpur [24], which face the challenges of car dominace, deteriance, and sociophysological issues. Locally, in Western Europe, people have the opportunity to decide for themselves due to monetary and legislative freedom. Climate debates within developed countries led to populistic knowledge development, stimulating users toward interaction with nature. In Flanders mainly, cycling provides ample opportunity for accessibility, more individual transport, and more interaction with nature.

Figure 9a shows mixed responses which are distributed very evenly among different risk levels. More respondents consider current systems as safe but still think significant improvements are needed, especially when looking at intersections. A strange contradiction was noticed among respondents who rated the current system as "Disaster, and do not consider cycling" but are still considering subconsciously current systems as "Safe". The conclusion in Figure 9a agrees with Visschers and Siegrist [49] that risk perception varies depending upon a psychometric paradigm shift related to elements such as dread and unknown risk. Thus, this strange notion is considered lying in a space between dread and unknown risk, explaining the difference in risk perception not knowingly, subconsciously, yet expressing cognitively and evolving inside. This is an interesting finding, but the reasons behind such a motive need to be explained. A possible explanation behind such behavior is that people tend to change their responses due to knowledge acquisition during the survey. The overall majority of respondents tended to express their appreciation of cycling with care, which has been linked to infrastructure, presence of other vulnerable road users, and TDMs. Figure $9 \mathrm{~b}$ reveals the possibility of risk formation, considering different cognitive parameters that influence behavior. Figure $9 \mathrm{~b}$ further helps in forming a general-awareness spectrum (considering attributes related to risk formation) for cycling potentials inside cities having the possibility to change the attitude toward stimulating its further use. The risk-perception spectrum is considered adequate and reveals promising variability among cyclists' cognitive risk formation. The risk spectrum offers as a platform for potential attitudinal persuasion techniques, considering elements that contribute to risk formation. Those elements were categorized cognitively within a tangible and non-tangible manner, i.e., policy, safety, and infrastructure. The elements were considered for research after an in-depth analysis of the literature. It can be noted that user attitudinal formation is a complicated procedure involving multiple features from a distinct context. As noted in the spectrum of risk, a mixed risk-attitudinal perception is formed, evolving from "Most Safe to Most Risky". It is a functional validation since it is evident that humans react differently to situations depending on their subjective feeling. By the end of the research, users tended to be satisfied with current conditions but still expressed the notion of improvement with regard to the new mobility regulations in Flanders. As stated previously, user risk perception tends to be lower in relation to user experience. Thus, users tend to be satisfied with new mobility regulations since they are already proficient cyclists.

In this cluster adequately only, those elements were evaluated by users who were considered from "Most Safe" to "Most Risky". The users were presented with diverse questions from multiple aspects, later identifying latent variables. Under the "Safe" perimeter umbrella, users consider opting for public transport when problems arise, whereas users consider the use of a personal car as "Risky", due to the fact users were already inclined toward a more sustainable modal choice. A smaller cycled distance contributes to lesser exposure to the environment, whereas users considered it as a critical element and rate it as "Safe". An inclined preference for lower cycling distance was noted for lessexperienced cyclists in the age category 18-25. The prominent effect of weather conditions makes cycling a less-comfortable experience, yet this eventually reduces the speed of vehicles, which increases the pupil's perception or recognition periphery. Hilliness also reduces the speed of the vehicle, thus providing more opportunities for vision, recognition, and understanding; therefore, hilliness for cyclists 
contributes to "Safety", while road width contributes toward better flow, reducing the chance of interaction and exposure. For cyclist's road width attribute contributes to "Safety". The general idea of cycling through a green environment comes with lesser exposure to traffic variables and more attention toward individuality. Thus, for a cyclist who considers cycling through the green environment to be "Safe", estimation of safety cannot be measured by interest or affinity for nature. It shows an affinity for cycling through nature is considered "Safe" by pleasure cyclists.

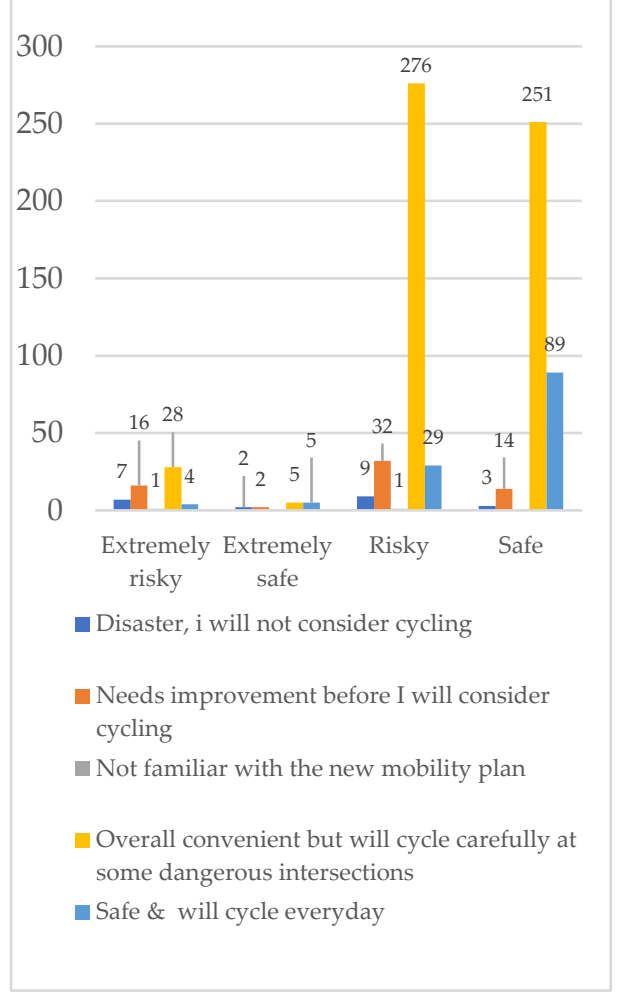

(a)

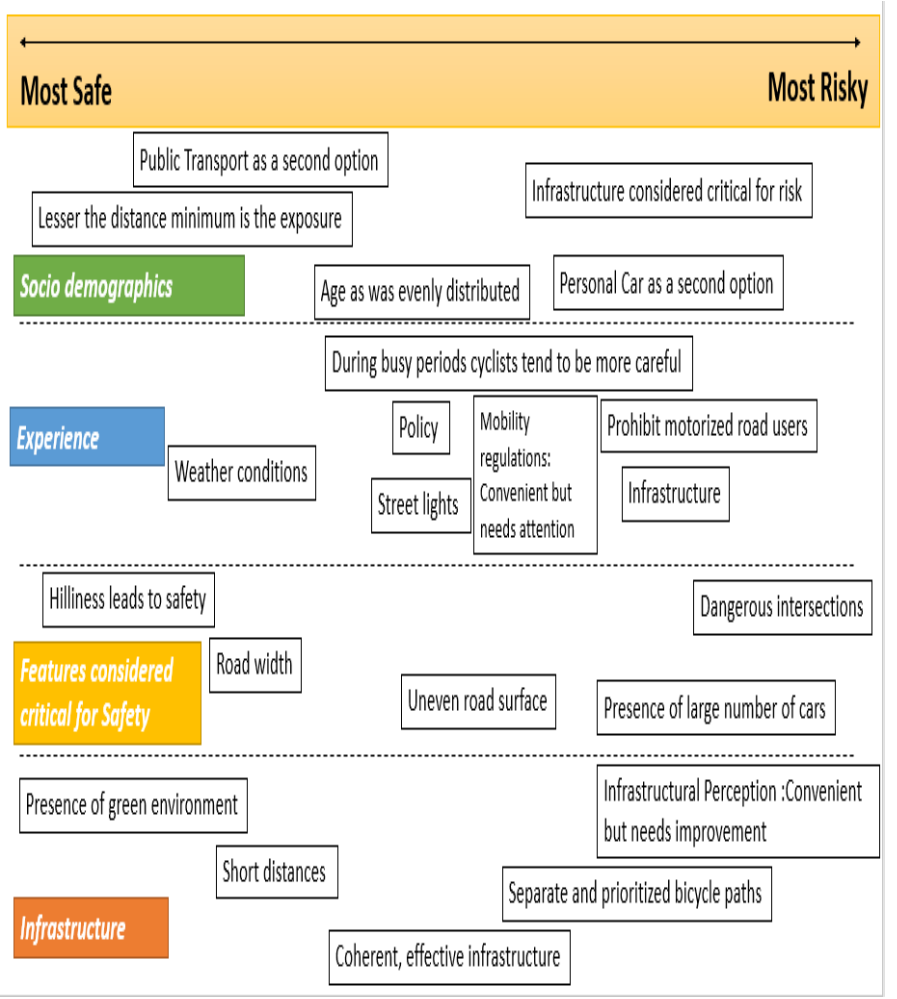

(b)

Figure 9. (a) Level of satisfaction for current measures; (b) spectrum of personality attributes associated for risk-perception formation when considering a bicycle.

The investigated users were already proficient in cycling in terms of experience and exposure. A possible explanation behind this is that cyclists having higher cycling skills tend to adapt their behavior and avoid risky situations. Their subjective feelings to deal with such conditions were considered to be handled comfortably. The users who rate this situation not risky nor extremely safe, i.e., neutral or no effect on perception formation are age, income, policy, streetlights, police presence, road surface, more vigilance during busy periods, the effectiveness of infrastructure, and coherency dependent upon new Flemish mobility regulations. Cyclists tend to be more careful during busy period due to the dominance of motorized road users, which makes non-motorized road users uncomfortable. Strangely enough, this is considered neutral by them, meaning that cyclists are used to such a practice and cognitively assume such routines to be a normal part of their life.

The visual spectrum helps visualize risky attributes considered by cyclists. Cyclists see opting for a "Personal car" only as a second option attributing to risk, since they already use a sustainable mode of transport and consider car-space occupancy to be attributing to risk increases. This may be connected to the effect of the presence of motorized road users, as well as non-motorized road users. As stated previously, "Safety in numbers" plays a significant role in the perception of safety. This may be negatively or positively associated: negative in terms of presence of opposite types of road users, and positive in terms of the presence of the same type of road users. As noted previously, the infrastructure itself is a tangible attribute that forms risk perception. Attributes such 
as dangerous intersections, multiple users in unsegregated lanes, presence of motorized road users, current bicycle paths, current mobility regulations, and perception during busy periods are associated with "Risk" formation.

Finally, it is essential to visualize a country's perspective over risk perception in order to get one step closer to behavioral formation based on tangible and non-tangible parameters. This would eventually help policymakers design better cycling policies and infrastructure that help stimulate the desire for cycling. Risk-perception visualization is critical, as it is an essential step before an attitude and behavior can change. Visualization, in particular with VRUs, is peculiar and novel in accident identification, but this appears to be of great importance since it yields a comprehensive, in-depth understanding of perception formation. Risk-formation periphery, when considering cyclists, is of great use for decision-makers, psychologists, and engineers, as it helps them construct and mold new mobility policies and decisions. Policymakers have a positive inclination toward cycling, especially in the Benelux context. The visual illustration for cycling advocates for its supports identifies and justifies it lacks for risk identification. This will eventually help to mitigate strategies toward cycling- friendly, safe infrastructure.

\section{Conclusions}

This study associates a cyclist's behavioral risk formation with experience, infrastructure, stimuli, and sociodemographic elements. It elaborates on cyclist perception regarding tangible and non-tangible attributes. The conclusion of this study is interesting since it has been highlighted how risk formation evolves around personal attributes, peer pressure, hinderance, policy, infrastructure, and geometry. At the same time, the investigated attributes are associated with experience, peer presence, accidents, aggressive road-user presence (motorized road user), policy, geometry, attractiveness, distance, and weather conditions.

The cyclists responded to questions regarding safety issues. Experienced cyclists rated conditions as "Risky" due to their exposure rate, whereas distance is considered as a safety indicator among them. Large distances lead to higher exposure, hence resulting in more "Risky" stimuli. The presence of a green environment shifts the cognitive priorities of risk engagement connected with infrastructure, thus gradually shifting from "safety" toward "attractiveness". Current mobility regulations were rated as "Safe", but with much room for improvement; a possible explanation is that those new regulations did not possess infrastructural improvements, since if those included infrastructural improvements, the cognitive satisfaction levels would have altered. The respondents considered infrastructural changes to be a critical predictor of safety, i.e., lane segregation resulting in lesser exposure and elevation resulting in more visibility.

Moreover, higher segregation of lanes results in higher comfort levels, providing lesser interaction with other road users. The safety-in-numbers effect is dominant among experienced cyclists, while, surprisingly, geometrical features, i.e., curvature, width, and hilliness, are not associated with "Risk". The comfort of using a bicycle path, which depends on surface conditions, is not rated as a critical predictor for safety. This can be viewed as the fact that the majority of bicycle paths are paved with "Asphalt", hence confirming with [47]. Thus, based on previous factors, a significant discrepancy is observed between perceived and actual risk formation.

In this manuscript, it is highlighted how perception attributes structurally evolve around personality, environment, stimuli, and experience for cyclists. When visualizing how cyclists' perceptions form, the cycling commute is considered to be a distinct practice. Various represented elements revolve around personal or nonpersonal attributes, i.e., policy and societal acceptance. As a result, in this study, policies, peer presence, attractiveness, environment, and infrastructure were identified to predict their involvement at the societal level, while their involvement with materials, competences, and meanings exists. The study highlights how cycling practice generates "Risky" and "Safety" perception influence on modal choice. Besides, it has been discussed in detail how policies, experiences, and infrastructure affect the transformation of the image of cycling in an "Active" and 
"Passive" manner. The analysis and conclusion of the study reflect of a particular region. For future studies, this study might be cross-validated with a dataset of another region/country that has similar conditions. Expanding responses or cross-validation from the same population sample will induce bias since the conditions have dramatically changed.

The approach taken in this paper leads to implications that can act as a basis for further cyclist modal policy development. The results have implications regarding the understanding of infrastructural influences, proximity, environmental conditions, and societal roles. This stimulates or reduces the obstructions for cycling, as well as minimizes circumstances reducing cyclists' risks.

Author Contributions: Conceptualization, Z.U.-A. and H.D.B.; data curation, Z.U.-A.; formal analysis, P.D.W.; investigation, Z.U.-A., and H.D.B.; methodology, Z.U.-A.; project administration, Z.U.-A., H.D.B., and P.D.W.; resources, H.D.B. and P.D.W.; software, Z.U.-A. and H.D.B.; supervision, Z.U.-A. and H.D.B.; validation, Z.U.-A. and H.D.B.; visualization, H.D.B. and P.D.W.; writing-original draft, Z.U.-A.; writing-review and editing, Z.U.-A. and H.D.B.

Funding: This research received no external funding.

Acknowledgments: The authors would like to thank the staff and students of the Department of Civil Engineering who helped in dissemination and data collection.

Conflicts of Interest: The authors declare no conflicts of interest.

\section{Abbreviations}

EU

European Union

TDMs transportation development measures

w. r. t. With respect to

VRUs vulnerable road users

\section{Appendix A}

Table A1. Frequency and percentage distribution of the investigated variables among different age classes.

\begin{tabular}{|c|c|c|c|c|c|c|c|c|}
\hline \multirow[t]{2}{*}{$\begin{array}{l}\text { Investigated Variables under Different } \\
\text { Age-Group Categories }\end{array}$} & \multicolumn{2}{|c|}{ Total } & \multicolumn{2}{|c|}{$18-25$} & \multicolumn{2}{|c|}{$25-40$} & \multicolumn{2}{|c|}{$40-65$} \\
\hline & Frequency & Percentage & Frequency & Percentage & Frequency & Percentage & Frequency & Percentage \\
\hline \multicolumn{9}{|c|}{ Socio-demographics } \\
\hline \multicolumn{9}{|l|}{ Gender } \\
\hline Female & 434 & 56 & 129 & 59 & 141 & 50 & 164 & 60 \\
\hline Male & 335 & 43 & 90 & 41 & 135 & 48 & 110 & 40 \\
\hline Prefer not to reveal & 5 & 0.6 & & & 4 & 1.4 & 1 & 0.4 \\
\hline \multicolumn{9}{|l|}{ Education } \\
\hline Bachelors & 284 & 37 & 82 & 0.4 & 84 & 30 & 118 & 43 \\
\hline High school diploma, i.e., ASO, BSO, TSO, KSO & 139 & 18 & 86 & 0.4 & 18 & 6.4 & 35 & \\
\hline Masters or higher & 316 & 41 & 43 & 0.2 & 168 & 60 & 105 & 38 \\
\hline Other & 16 & 2.1 & 3 & 0 & 6 & 2.1 & 7 & 2.5 \\
\hline $\mathrm{PhD}$ & 1 & 0.1 & & 0 & 1 & 0.4 & & 0 \\
\hline Technical Diploma & 18 & 2.3 & 5 & 0 & 3 & 1.1 & 10 & 3.6 \\
\hline \multicolumn{9}{|l|}{ Distance } \\
\hline $0-1 \mathrm{~km}$ & 37 & 4.8 & 23 & 11 & 9 & 3.2 & 5 & 1.8 \\
\hline $1-3 \mathrm{~km}$ & 134 & 17 & 63 & 29 & 43 & 15 & 28 & 10 \\
\hline $3-5 \mathrm{~km}$ & 160 & 21 & 14 & 6.4 & 31 & 11 & 9 & 3.3 \\
\hline $5-8 \mathrm{~km}$ & 412 & 53 & 31 & 14 & 34 & 12 & 41 & 15 \\
\hline Other & 14 & 1.8 & 82 & 37 & 149 & 53 & 181 & 66 \\
\hline More than $8 \mathrm{~km}$ & 17 & 2.2 & 1 & 0.5 & 5 & 1.8 & 8 & 2.9 \\
\hline \multicolumn{9}{|c|}{ Attitudes toward specific stimuli } \\
\hline \multicolumn{9}{|l|}{ Motivation for bicycle use } \\
\hline All of the above & 2 & 0.3 & & 0 & 2 & 0.7 & & 0 \\
\hline Better accessibility and no parking worries & 325 & 42 & 86 & 0.4 & 125 & 45 & 114 & 41 \\
\hline Cheaper than public transport/car & 94 & 12 & 42 & 0.2 & 31 & 11 & 21 & 7.6 \\
\hline $\begin{array}{l}\text { Good for the environment, cheap, healthy, } \\
\text { no queuing }\end{array}$ & 7 & 0.9 & 2 & 0 & 4 & 1.4 & 1 & 0.4 \\
\hline Incentives offered by employer/school & 40 & 5.2 & 3 & 0 & 19 & 6.8 & 18 & 6.5 \\
\hline It's healthy & 5 & 0.6 & 1 & 0 & 4 & 1.4 & & 0 \\
\hline Lesser congestion or long queuing & 110 & 14 & 31 & 0.1 & 39 & 14 & 40 & 15 \\
\hline Other & 186 & 24 & 53 & 0.2 & 52 & 19 & 81 & 29 \\
\hline quicker than public transport, autonomy & 5 & 0.6 & 1 & 0 & 4 & 1.4 & & 0 \\
\hline
\end{tabular}


Table A2. Frequency and percentage distribution of the investigated variables among different age classes.

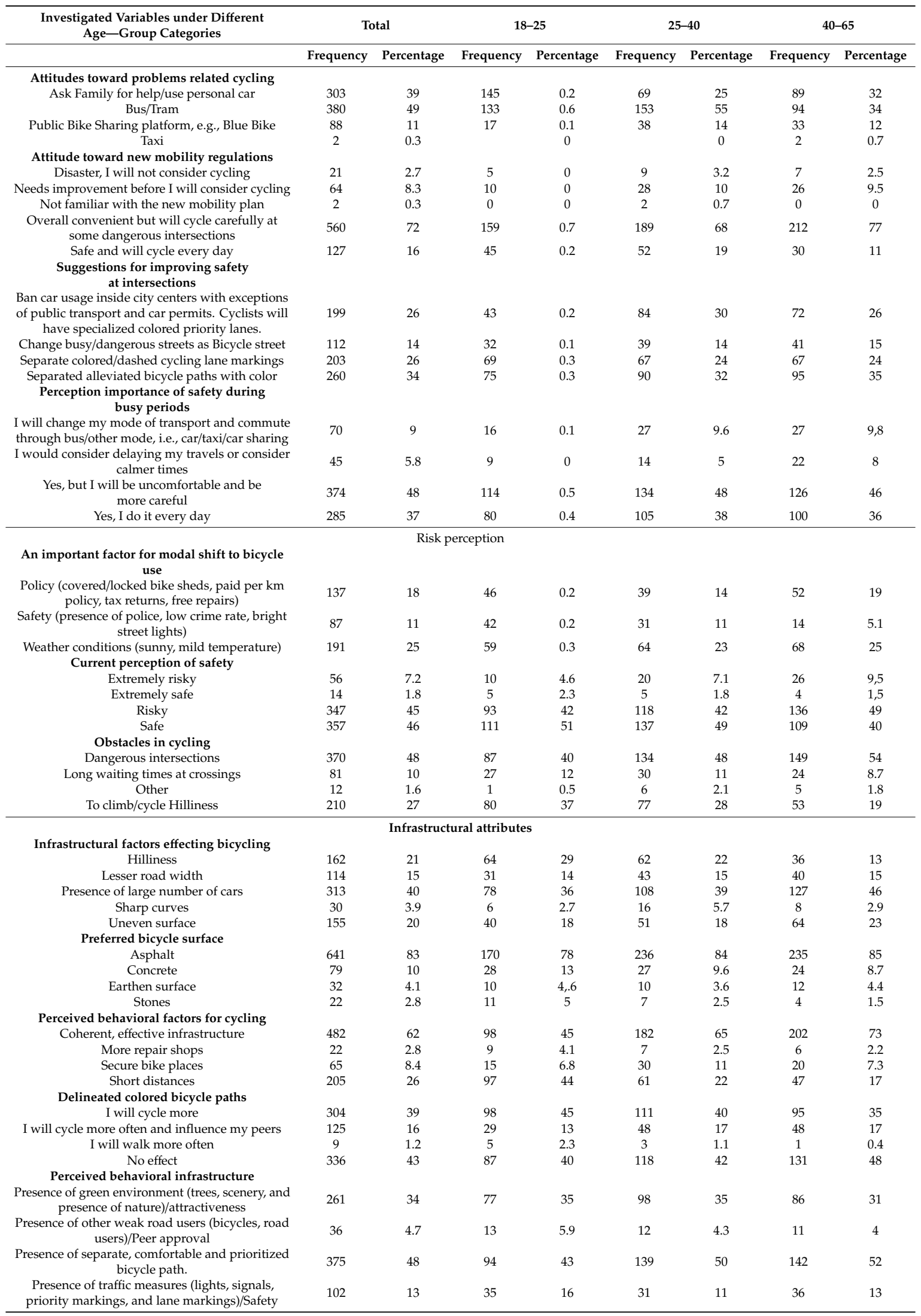




\section{References}

1. Koornstra, M.J. Risk-adaptation theory. Transp. Res. Part F Traffic Psychol. Behav. 2009, 12, 77-90. [CrossRef]

2. Jensen, S.U. Pedestrian and bicyclist level of service on roadway segments. Transp. Res. Rec. 2007, 2031, 43-51. [CrossRef]

3. Aldred, R.; Crosweller, S. Investigating the rates and impacts of near misses and related incidents among UK cyclists. J. Transp. Health 2015, 2, 379-393. [CrossRef]

4. Jacobsen, P.L. Safety in numbers: More walkers and bicyclists, safer walking and bicycling. Inj. Prev. 2015, 21, 271-275. [CrossRef]

5. WILDE, G.J.; Murdoch, P.A. Incentive systems for accident-free and violation-free driving in the general population. Ergonomics 1982, 25, 879-890. [CrossRef]

6. Ajzen, I. The theory of planned behaviour. Organizational Behaviour and Human Decision Processes, 50, 179-211. De Young 1991, 50, 509-526.

7. Windsor, T.D. Behavioral approach and behavioral inhibition as moderators of the association between negative life events and perceived control in midlife. Personal. Individ. Differ. 2008, 44, 1080-1092. [CrossRef]

8. Kaplan, S.; Wrzesinska, D.K.; Prato, C.G. Transportation Research Board 98th Annual Meeting. In Proceedings of the Psychosocial Benefits and Mood Improvement from Habitual Bicycle Use, Washington, DC, USA, 13-17 January 2019.

9. Puchades, V.M. The role of perceived competence and risk perception in cycling near misses. Saf. Sci. 2018, 105, 167-177. [CrossRef]

10. Pucher, J.; Dill, J.; Handy, S.J.P.M. Infrastructure, programs, and policies to increase bicycling: An international review. Prev. Med. 2010, 50, S106-S125. [CrossRef]

11. Rode, P. Accessibility in Cities: Transport and Urban Form. In Disrupting Mobility: Impacts of Sharing Economy and Innovative Transportation on Cities; Meyer, G., Shaheen, S., Eds.; Springer International Publishing: Cham, Switzerland, 2017; pp. 239-273.

12. Steg, L. Factors influencing the acceptability and effectiveness of transport pricing. In Acceptability of Transport Pricing Strategies; Pergamon Press: Oxford, UK, 2003; pp. 187-202. Available online: https: //doi.org/10.1108/9781786359506-012 (accessed on 25 February 2018).

13. Reutter, O.J.E.B. The 'YOU-move. nrw'campaign-New partnerships for youth-oriented and environmentally friendly mobility management Oscar Reutter. Editor. Board 2004, 10, 15-21.

14. Noland, R.B.; Ishaque, M.M. Smart bicycles in an urban area: Evaluation of a pilot scheme in London. J. Public Transp. 2006, 9, 5. [CrossRef]

15. Rybarczyk, G.; Gallagher, L. Measuring the potential for bicycling and walking at a metropolitan commuter university. J. Transp. Geogr. 2014, 39, 1-10. [CrossRef]

16. Gårder, P.; Leden, L.; Thedéen, T. Safety implications of bicycle paths at signalized intersections. Accid. Anal. Prev. 1994, 26, 429-439.

17. Madsen, T.K.O.; Lahrmann, H. Comparison of five bicycle facility designs in signalized intersections using traffic conflict studies. Transp. Res. Part F Traffic Psychol. Behav. 2017, 46, 438-450. [CrossRef]

18. Ul-Abdin, Z. Ride Quality for Bicycle Paths under Different Pavement Conditions. In Proceedings of the International Conference on Transportation and Development, Pittsburg, CA, USA, 15-18 July 2018.

19. Cantisani, G.; Moretti, L.; De Andrade Barbosa, Y. Safety Problems in Urban Cycling Mobility: A Quantitative Risk Analysis at Urban Intersections. Safety 2019, 5, 6. [CrossRef]

20. Pucher, J.; Buehler, R. Safer Cycling Through Improved Infrastructure. Am. J. Public Health Assoc. 2016, 106, 2089-2091. Available online: https://ajph.aphapublications.org/doi/10.2105/AJPH.2016.303507 (accessed on 10 December 2018). [CrossRef]

21. Sammer, G. A General 30 km/H Speed Limit in the City: A Model Project in Graz, Austria; Wiley \& Sons Ltd.: Chichester, UK, 1997; pp. 385-390.

22. Bakogiannis, E. Developing a sustainable mobility plan in Piraeus with special emphasis on cycling. J. Traffic Transp. Eng. 2016, 4, 61-74.

23. Sanders, R.L. Perceived traffic risk for cyclists: The impact of near miss and collision experiences. Accid. Anal. Prev. 2015, 75, 26-34. [CrossRef] 
24. Shokoohi, R.; Nikitas, A. Urban growth, and transportation in Kuala Lumpur: Can cycling be incorporated into Kuala Lumpur's transportation system? Case Stud. Transp. Policy 2017, 5, 615-626. [CrossRef]

25. Useche, S.A. Healthy but risky: A descriptive study on cyclists' encouraging and discouraging factors for using bicycles, habits and safety outcomes. Transp. Res. Part F Traffic Psychol. Behav. 2019, 62, 587-598. [CrossRef]

26. Willis, D.P.; Manaugh, K.; El-Geneidy, A. Cycling under influence: Summarizing the influence of perceptions, attitudes, habits, and social environments on cycling for transportation. Int. J. Sustain. Transp. 2015, 9, 565-579. [CrossRef]

27. Gössling, S. Effects of perceived traffic risks, noise, and exhaust smells on bicyclist behaviour: An economic evaluation. Sustainability 2019, 11, 408. [CrossRef]

28. Deery, H.A. Hazard and risk perception among young novice drivers. J. Saf. Res. 1999, 30, $225-236$. [CrossRef]

29. Strauss, J.; Miranda-Moreno, L.F.; Morency, P. Cyclist activity and injury risk analysis at signalized intersections: A Bayesian modelling approach. Accid. Anal. Prev. 2013, 59, 9-17. [CrossRef] [PubMed]

30. Kummeneje, A.M.; Ryeng, E.O.; Rundmo, T. Seasonal variation in risk perception and travel behaviour among cyclists in a Norwegian urban area. Accid. Anal. Prev. 2019, 124, 40-49. [CrossRef] [PubMed]

31. Prati, G. The Role of Perceived Competence and Risk Perception in Cycling Near Misses. PsyArXiv: Web. 5 April 2019. Available online: https://psyarxiv.com/wy64s/ (accessed on 10 July 2019).

32. Yao, L.; $\mathrm{Wu}, \mathrm{C}$. Traffic safety for electric bike riders in China: Attitudes, risk perception, and aberrant riding behaviors. Transp. Res. Rec. 2012, 2314, 49-56. [CrossRef]

33. Ulleberg, P.; Rundmo, T. Personality, attitudes and risk perception as predictors of risky driving behaviour among young drivers. Saf. Sci. 2003, 41, 427-443. [CrossRef]

34. Şimşekoğlu, Ö.; Nordfjærn, T.; Rundmo, T. Traffic risk perception, road safety attitudes, and behaviors among road users: A comparison of Turkey and Norway. J. Risk Res. 2012, 15, 787-800. [CrossRef]

35. Nordfjærn, T.; Jørgensen, S.; Rundmo, T. A cross-cultural comparison of road traffic risk perceptions, attitudes towards traffic safety and driver behaviour. J. Risk Res. 2011, 14, 657-684. [CrossRef]

36. Nordfjærn, T.; Rundmo, T. Perceptions of traffic risk in an industrialised and a developing country. Transp. Res. Part F Traffic Psychol. Behav. 2009, 12, 91-98. [CrossRef]

37. Heinen, E.; Maat, K.; Van Wee, B. The role of attitudes toward characteristics of bicycle commuting on the choice to cycle to work over various distances. Transp. Res. Part D Trans Environ. 2011, 16, 102-109. [CrossRef]

38. Dufour, D. PRESTO Cycling Policy Guide-General Framework. Intell. Energy-Eur; PRESTO: Brussels, Belgium, February 2010.

39. Groot, R.D. Design Manual for Bicycle Traffic. National Academy of Sciences. 2007. Available online: https://trid.trb.org/view/1153223 (accessed on 23 February 2019).

40. Thomas, B.; DeRobertis, M. The safety of urban cycle tracks: A review of the literature. Accid. Anal. Prev. 2013, 52, 219-227. [CrossRef] [PubMed]

41. Akar, G.; Clifton, K.J. Influence of individual perceptions and bicycle infrastructure on decision to bike. Transp. Res. Rec. 2009, 2140, 165-172. [CrossRef]

42. Dill, J.; McNeil, N. Four types of cyclists? Examination of typology for better understanding of bicycling behavior and potential. Transp. Res. Rec. 2013, 2387, 129-138. [CrossRef]

43. Townsend, E. The European Union's Role in Promoting the Safety of Cycling: Proposals for a Safety Component in a Future EU Cycling Strategy; National Academy of Sciences: Brussels, Belgium, 2016.

44. Fishman, E.; Schepers, P.; Kamphuis, C.B.M. Dutch cycling: Quantifying the health and related economic benefits. Am. J. Public Health 2015, 105, e13-e15. [CrossRef]

45. DiGioia, J. Safety impacts of bicycle infrastructure: A critical review. J. Saf. Res. 2017, 61, 105-119. [CrossRef]

46. Saad, M. Bicycle Safety Analysis at Intersections from Crowdsourced Data. Transp. Res. Rec. 2019, 2673, 0361198119836764. [CrossRef]

47. Ul-Abdin, Z. Analytical geometric design of bicycle paths. In Proceedings of the Institution of Civil Engineers-Transport; Thomas Telford Ltd.: London, UK, 4 June 2018; pp. 1-19. Available online: https://www.icevirtuallibrary.com/doi/10.1680/jtran.17.00162 (accessed on 8 August 2018). 
48. Dill, J. Bicycling for transportation and health: The role of infrastructure. J. Public Health Policy 2009, 30, S95-S110. [CrossRef]

49. Visschers, V.H.; Siegrist, M. Differences in Risk Perception between Hazards and between Individuals. Psychological Perspectives on Risk and Risk Analysis; Springer: Cham, Switzerland, 2018; pp. 63-80.

(C) 2019 by the authors. Licensee MDPI, Basel, Switzerland. This article is an open access article distributed under the terms and conditions of the Creative Commons Attribution (CC BY) license (http://creativecommons.org/licenses/by/4.0/). 